\title{
LA LITERATURA ANTIPERONISTA DE J. R. WILCOCK.
}

\author{
POR \\ DANIEL BALDERSTON \\ Tulane University
}

La diáspora latinoamericana de los últimos años ha hecho que muchos: intelectuales latinoamericanos se encuentren dispersos por el mundo, en muchos casos integrados a sus nuevos países a la vez que añoran la patria que tuvieron que dejar. Es una historia antigua, en realidad: vale recordar el ejemplo de Rafael Landívar, jesuita guatemalteco que escribió su Rusticatio mexicana en Viena a fines del siglo xviII. Otro ejemplo notable: el poeta y narrador argentino Juan Rodolfo Wilcock, quien desde Italia, donde vivió los últimos veinte años de su vida, escribió una serie de obras en italiano, en muchas de las cuales medita sobre la patria lejana. Su novela L'ingegnere, por ejemplo, retrata a un joven ingeniero muy culto que trabaja en la reconstrucción del ferrocarril trasandino, quejándose de su soledad (y alimentándose de un manjar singular: la carne de los niños de sus vecinos): una evidente revalorización del tópico más importante de la literatura argentina, «civilización y barbarie».

Wilcock se fue de la República Argentina en 1954, para nunca volver. Como muchos escritores argentinos, sufrió profundos disgustos durante el primer peronismo, y su antiperonismo se ve inscrito en su obra de ese momento y de los años siguientes, de manera menos sutil que en los casos estudiados recientemente por Andrés Avellaneda en El habla de la ideología (donde dedica ensayos a las obras de ficción de Bustos Domecq, el primer Cortázar, Martínez Estrada y Anderson Imbert). Avellaneda muestra que el antiperonismo de estos escritores se expresa soslayadamente en la manera de retratar a los personajes populares y en el tratamiento de códigos linguíisticos y sociales. Declara que el contenido antiperonista rara vez se expresa directamente en estos escritores. En cambio, Wilcock se declara claramente antiperonista al publicar en primera plana de su revis-- 
ta de poesía, Disco, en 1946, esta frase de Tocqueville sobre el despotismo y la libertad: «El despotismo me parece particularmente terrible en tiempos de democracia. Yo creo que en cualquier época habría amado la libertad, pero en esta época nuestra me siento más bien inclinado a adorarla» ${ }^{1}$. El cuento que Wilcock le dedica a Evita, «Casandra», quiere denunciar de manera inequívoca el ambiente de tortura, degradación y violencia que su autor siempre asoció con el peronismo.

En el cuento, el cual es evidentemente una reescritura de «La lotería en Babilonia», de Borges, Casandra, quien «fue en un principio una vagabunda similar a esas miles de desdichadas, jóvenes y viejas, que habiendo perdido la razón recorren de día nuestros caminos cantando melodías que por un error creemos tradicionales» (p. 163) ${ }^{2}$, pasa a tener funciones importantes en el Arcontado de Entretenimientos y luego a ser el árbitro supremo no sólo de los gustos, sino de la vida y la muerte de sus súbditos. Estos se preguntan cómo ha podido subir a una posición de tanto poder: «¿Acaso alguna mujer llegó jamás a gozar de semejante predominio entre nosotros? No; por lo tanto, ¿no es natural que para lograr ese fin inaudito utilizara métodos que por fuerza deben de parecer inauditos?» (p. 162).

El método inaudito de Casandra (y aquí la influencia del cuento de Borges se hace patente) es su aparente falta de método, su arbitrariedad exquisita. Si un día admira la bufanda colorada que lleva un suplicante y le regala una suma fabulosa de dinero, al día siguiente los suplicantes que aparecen llevando bufandas coloradas pierden dientes, cejas, uñas. Cuando comienza a regalar torturas y muertes en vez de riquezas a los suplicantes, el número de éstos aumenta, sobre todo de los pobres, «los que no tenían nada que perder, salvo un cuerpo habituado a la desdicha» (p. 166). Comenta el narrador: «Casandra, desde las tinieblas de su demencia, conforma a todos desconcertando a todos» (p. 161). El caos, como bien se nota en otro cuento de Wilcock, agrada a la gente, rescatándolos de la monotonía de la vida cotidiana ${ }^{3}$.

Casandra, por ser imprevisible en sus acciones y sus palabras, suscita reacciones contradictorias (y se contradice a sí misma). Su lenguaje peculiar, amalgama de idiomas desconocidos y olvidados, despierta la admiración de los lingüistas, quienes escriben «libros y tesis de doctorado sobre

${ }^{1}$ Disco, núm. 5 (junio 1946).

${ }^{2}$ Las páginas entre paréntesis al final del texto citado remiten a la edición argentina de los cuentos de Wilcock, El caos (Buenos Aires: Editorial Sudamericana, 1974).

${ }^{3}$ Para un comentario sobre el cuento «El caos», véase mi artículo «Los cuentos crueles de Silvina Ocampo y Juan Rodolfo Wilcock», Revista Iberoamericana, número 125 (octubre-diciembre de 1983), especialmente p. 749. 
sus modalidades lingüísticas... Ninguno de estos estudios concuerda con ningún otro; y ésta es tal vez la casualidad más notable de Casandra: suscitar opiniones que nadie comparte, que nadie quiere ni siquiera escuchar, mucho menos leer» (p. 161). Frase que recuerda la multiplicidad de reacciones ante La razón de mi vida, libro tratado como escritura sagrada por algunos, como tejido irrisorio de mentiras por otros ${ }^{4}$. Otra astucia más cruel de Wilcock: al escribir que todos afirman que Casandra es extranjera por los defectos de pronunciación y los giros foráneos en su habla, pero que todos le atribuyen nacionalidades diferentes, nos podría recordar la variedad de opiniones suscitada por el habla del asesino en «The Murders in the Rue Morgue» de Poe, quien resulta ser orangután.

Los chismes que se cuentan de Casandra - su origen dudoso, su pasado de vagabunda, su vanidad, su fascinación por los vestidos y las «posturas memorables» (p. 162) - nos recuerdan forzosamente los chismes que circulaban en torno a Evita ${ }^{5}$. Hasta su aparente belleza es motivo de dudas: «Despojada del aparato que la rodea, ¿qué quedaría de su belleza? $\mathrm{Su}$ pelo teñido, su nariz aguileña, sus dientes protuberantes y sus demás defectos hasta podrían, aunque esto sólo es una suposición y el pasado ha demostrado que no es posible forjar impunemente suposiciones, hasta podrian inspirar repugnancia a los amantes que hoy se arrojan a su paso» (p. 164) ${ }^{6}$. De Casandra se dice que «las ofrendas particulares que recibe son a veces valiosas, pero ella las gasta inmediatamente en locuras y trapos. El resto pertenece al Arcontado de Entretenimientos... Por otra parte, las riquezas no le interesan; sólo goza con el poder, con la arbitrariedad», todo lo cual nos quiere recordar lo que decían las malas lenguas de Evita y su Fundación ?.

En suma, "Casandra» nos ofrece la imagen de una mujer que fascina al narrador y a sus parientes por la astucia con que maneja el poder, utilizando una mezcla de generosidad y crueldad que escapa a toda regla, en un comportamiento loco e injusto. Los juicios de los admiradores de Casandra - de que es bella, interesante, inteligente- se presentan como comentarios interesados. Cuando los admiradores dicen, por ejemplo, «que a su lado uno siente lo que no se siente al lado de ninguna mujer..., los detractores se dicen sardónicamente en voz baja: la esperanza de hacerse rico» (p. 164). El sentimiento que más inspira Casandra en el narrador es

\footnotetext{
${ }^{4}$ Véase Joseph Page, Perón: A Biography (New York: Random House, 1983), pp. $255-256$.

${ }_{5}^{5}$ Véase Page, pp. 82-83.

${ }^{6}$ Page, por ejemplo, dice: «she was neither stunning nor vocally gifted» (p. 82), y se refiere a su pelo teñido en la p. 84 .

7 Véase Page, pp. 112-113.
} 
el miedo: el cuento termina a las cuatro de la tarde, cuando todos miran nerviosamente el reloj, sabiendo que a esa hora "Casandra acomoda alrededor del trono sus velos, sus colas de encaje y sus armiños, y ordena que entren los suplicantes» (p. 167).

Otro cuento de Wilcock que toca de manera tangencial el gobierno peronista es «La noche de Aix», relato de un argentino, Falcone, que vive en Francia, donde sueña con la patria lejana. Sueña con un bombardeo de Buenos Aires: «Era una revolución contra el dictador, que en el sueño se llamaba Conejo, y la población daba grandes muestras de entusiasmo. Falcone paseaba solo entre multitudes aterradas aunque dichosas; dos o tres bombas caían cerca de él, pero pronto aprendía a eludir sus efectos» (pp. 112-113). La referencia evidente es el bombardeo de la Plaza de Mayo el 16 de junio de 1955, preludio de la «Revolución Libertadora». Como se ve, Wilcock elude mencionar directamente a Perón, aunque logra insultarlo llamándolo Conejo ${ }^{8}$.

Wilcock, como ya he dicho, se fue de la Argentina en los últimos años del primer peronismo y no regresó nunca aun después de la llamada «Revolución Libertadora». Se alejó no sólo del país, sino también del idioma, convirtiéndose en un escritor italiano de primer orden. Pero, a pesar de todo, siguió siendo profundamente argentino en la temática de sus obras y en ese cosmopolitismo irreverente que aprendió de Borges. Antes de alejarse del todo del idioma español, mientras vivía en Londres escribiendo notas sobre literatura inglesa para la revista literaria porteña Ficción, escribió un fascinante poema explicando su exilio y su obsesión con la patria. «De un argentino a la República», escrito en 1957 y publicado ahora gracias a la gentileza del hijo del escritor, Livio Bacchi Wilcock, es un poema de amor no correspondido: un poema político que revaloriza el lenguaje convencional de la poesía amorosa ${ }^{9}$.

\footnotetext{
\& Para un comentario sobre este y otros escritos de Wilcock, véase el artículo de Luis Chitarroni «La nieve y su reflejo», en Sitio, núm. 3 (agosto de 1983), pp. 10-15.

${ }^{9}$ El tema del exilio aparece en la poesía de Wilcock mucho antes que en su experiencia vital: en Ensayos de poesía lírica (Buenos Aires, 1945) hay un poema dedicado al hijo pródigo (pp. 23-25) y otro titulado «Del destierro» (pp. 52); en Persecución de las musas menores (Buenos Aires, 1945), el poema «El exilado» habla del exilio de Ovidio al Mar Negro, y dice: «Así también, flotando en el paisaje / silencioso y extático, imagino / bajo un cielo muy blanco mi destino / indefinido y lento como un viaje» (p. 20).
} 
DE UN ARGENTINO A LA REPUBLICA

Como una mujer joven dormida en la tormenta, como una anestesiada sobre la tierra esférica, te vi desnuda y sucia tendida sobre América mostrando entre tus restos de túnica harapienta tus ríos, tus montañas plagadas de ratones, Buenos Aires roído de herrumbre y de ladrones y en cada arroyo seco una osamenta.

Vi en tus ciudades damas mordidas por chacales y en el medio del campo carteles con consignas; de noche se escuchaban carcajadas malignas por las calles desiertas de algunos arrabales, o al pasar por la esquina de un café trasparente la voz de un atorrante que insultaba a la gente por la red de las radios oficiales.

¿Y es ésta la República, pensé, que tanto amabas, la alumna distinguida de Inglaterra y de Francia? ¿Son éstas las provincias que pintaste en la infancia, las plazas, con estatuas donde te enamorabas? Acostada entre víboras esa inmensa mujer bajo las nubes, bajo las lluvias, ¿puede ser tan al revés de lo que imaginabas?

Patria, me rechazaste sin mirarme siquiera, preferías los besos de tus negros demonios; estabas loca, loca, te adornabas con moños que encontrabas tirados, como una basurera, y me decías: "Vete, no quiero mamarrachos, no quiero ni violines ni libros, quiero machos que me estremezcan una vida entera.»

Estabas orgullosa con tu nueva postura de adúltera sin frenos, de novia del bandido que se acuesta en la selva sin cambiar de vestido, pero ya no cantabas, ni eras feliz, ni pura, y cuando levantabas tus pupilas ya frías hacia la luna azul de invierno repetías: «Vete, vete, no quiero tu ternura.»

Te dormías, enorme, sobre tus ríos lentos con bagres y con frutas que navegan absortas, 
sola y hecha una india con las polleras cortas, mi tesoro, mi nido de lagunas y vientos; decías que era el turno de amar a un asesino, que si también los malos tramaban tu destino también se merecían monumentos.

Nubes de hormigas negras devoraban tus senos y tus pobres adornos colgaban en pedazos entre los eslabones que te ataban los brazos a una pared cubierta de retratos obscenos, y aun así deslumbrabas a los Embajadores mostrándoles tus deltas o tus bosques sin flores o un volcán con relámpagos y truenos.

Y una tarde entendí que eras invulnerable, que los hombres pasaban por ti sin conmoverte porque les dabas vida como les dabas muerte, que tu última razón era inconjeturable frente a tu eternidad de mares y cascadas y avalanchas de piedras y selvas incendiadas, frente a tu mismo nombre intrasmutable.

Como el amante mira sobre el lecho a su amada desnuda entre las sábanas aún cálidas, te vi desde el Cabo de Hornos hasta Orán y Yaví espléndida y dormida, y aparté la mirada, débil de celos porque tu lecho no era el mío, y en un barco extranjero me alejé por el Río a esperar exilado tu alborada.

A esperar ese instante de lluvia y primavera, cuando abriendo los ojos con vaga majestad barrieras hacia el agua las ratas de ciudad que te habían comido la vestimenta entera, y adornada otra vez con tus constelaciones contestaras el canto de las demás naciones envuelta solamente en tu bandera.

Las dos comparaciones con que abre el poema ( Como una mujer joven dormida en la tormenta, / como una anestesiada sobre la tierra esférica») proponen ya una doble lectura. Dos versiones de la misma imagen: una romántica, la otra grotesca. La República Argentina es a la vez esa joven inocente ante el desastre inminente y una enferma cuyo sueño es el del «patient etherised upon a table» de Eliot. Los adjetivos del verso si- 
guiente confirman esta yuxtaposición: «te vi desnuda y sucia». El resto de la estrofa nos presenta un paisaje corrompido: las montañas están «plagadas de ratones», los ríos de esqueletos, la ciudad de ladrones. La segunda estrofa continúa insistiendo en la degradación tanto del campo como de la ciudad, y revela el motivo de esta degradación: «la voz de un atorrante que insultaba a la gente / por la red de las radios oficiales». E1 insultador insultado: el vocablo «atorrante» (derivado, según Abad de Santillán, de aquel A. Torrent que hizo construir los desagües del Paseo de Julio, lugar que sirvió «largo tiempo de habitáculo a gentes sin hogar $y$ sin oficio» ${ }^{10}$ ) establece distancia y desprecio hacia la figura del presidente odiado. Más adelante, en la séptima estrofa, al referirse a los carteles en las paredes con los retratos del presidente y su mujer, se negará otra vez a nombrarlos, calificando estos carteles sucintamente de «retratos obscenos».

Hasta aquí, el que habla es el yo, la República es el tú. Sin embargo, en la tercera estrofa el yo se desdobla y se trata de tú, para recordar la infancia, el idealismo, el primer amor. Nótese que la imagen of recida de 1a República Argentina es altamente «europeizante»: es «la alumna distinguida de Inglaterra y de Francia», colegiala que se encuentra ahora tirada a la intemperie o anestesiada en la mesa de operaciones, hasta «acostada entre víboras». El idealismo violentado del que habla, que será un elemento importante del resto del poema, se enuncia por primera vez en los versos del desengaño:

Acostada entre víboras esa inmensa mujer bajo las nubes, bajo las lluvias, ¿puede ser tan al revés de lo que imaginabas?

La imagen idealizada resulta ser el contrario absoluto de la mujer real, degradada: la diferencia insalvable entre las dos imágenes determinará más adelante la expulsión del poeta.

La cuarta estrofa repite las palabras adoloridas de un sinnúmero de poetas que sufren del amor no correspondido, con la diferencia de que la amada es la Madre Patria y los otros pretendientes los «cabecitas negras», que Wilcock retrata con un racismo abierto como «negros demonios». La Patria se convierte en prostituta, en basurera; sus palabras implican un rechazo de toda la cultura europea en el país: «Vete, no quiero mamarrachos, / no quiero ni violines ni libros, quiero machos / que me estremez-

${ }^{10}$ Diego Abad de Santillán, Diccionario de argentinismos de ayer y de hoy (Buenos Aires: Tipográfica Editora Argentina, 1976), p. 35. 
can una vida entera». La cultura se presenta como andrógino o afeminado frente al nuevo ideal del negro demonio con sus consabidos atributos sexuales. La República, mientras tanto, se ve transformada por sus nuevos amores en «novia del bandido» y en «india con las polleras cortas», imágenes que remiten a los estereotipos de la literatura argentina del siglo pasado con su ecuación entre el indio y el gaucho malo y su insistencia en las mujeres fáciles que pasaban de un bando a otro. Al final de la sexta estrofa la República proclama «que era el turno de amar a un asesino, / que si también los malos tramaban tu destino / también se merecían monumentos», razonamiento repugnante para el que habla por el divorcio absoluto que propone entre la moralidad y la política. El poeta, amante rechazado, se identifica implícitamente con la tradición liberal que viene de Sarmiento y Alberdi y que quiere transformar al país según modelos foráneos. El país, mientras tanto, se muestra poco dispuesto a transformarse según sus designios, prefiriendo lo autóctono (el negro, el indio, la vida rural). Aunque el poeta insiste que la República no es «feliz, ni pura», tiene que reconocer que es indudablemente dueña de sí: enorme, fuerte, absorta en su nuevo amor.

La imagen de la mujer degradada en la séptima estrofa — devorada por hormigas negras (que recuerdan al famoso gaucho matrero de Eduardo Gutiérrez), harapienta, atada con cadenas a una pared- podría hacernos pensar en la española del cuento de Wilcock «La engañosa», cuyo cuerpo minado es nido no de «lagunas y vientos», sino de hormigas, dientecitos, trampas para conejos y descargas eléctricas ${ }^{11}$. La ciudad se encuentra afeada con los «retratos obscenos» del presidente y su mujer, y el campo yermo, sin flores, lleno de hormigas. Pero a pesar de su degradación, la República deslumbra con su belleza salvaje - sus deltas, sus bosques sin flores, sus volcanes en erupción-, imágenes románticas de una naturaleza trágica.

En la octava estrofa, en mi opinión la mejor del poema, el hablante narra su descubrimiento de que la degradación no es transitoria, sino permanente. Ese descubrimiento se revela en tres adjetivos rimados: invulnerable, inconjeturable, intrasmutable. La República es enorme, fuerte e indiferente: a sus ciudadanos «les dabas vida como les dabas muerte». Su naturaleza es feroz en su esencia: es una «eternidad de mares y cascadas / y avalanchas de piedras y selvas incendiadas». Y es, como el metal noble que le dio nombre, incapaz de ser trasmutada en otra cosa. Ajena al hombre, se revela su enemigo.

" Para una discusión de «La engañosa», véase mi artículo sobre Ocampo y Wilcock citado en nota 3, pp. 751-752. 
La penúltima estrofa, que narra el exilio del poeta, retoma la imagen de los amantes, insistiendo nuevamente en el contraste entre el hombre sensible y débil y la mujer espléndida, fuerte y enorme. Si ella fue al comienzo «la alumna distinguida de Inglaterra y de Francia», él se revela acá como escolar, mirando el mapa con ojos lascivos. Aparta la mirada y se aparta - «tu lecho no era el mío»-, ya que no tiene la fuerza de un río, un volcán o una avalancha de piedras. Se aleja en un barco extranjero para esperar exilado: su expulsión se convierte en espera.

¿Espera de qué? Si antes declaró que la República era indiferente a sus ciudadanos y arraigada en su barbarie, ¿cómo puede esperar un momento de alborada, de lluvia, de primavera? Las imágenes remiten otra vez a los estereotipos románticos de la naturaleza, que puede ser salvaje pero también inocente, horrible y bella. Esta «belle dame sans merci» lo tiene preso aun en su exilio: preso a su imagen idealizada y a la espera de un nuevo comienzo. El día que espera - cuando las «ratas de ciudad» se barran hacia el Río y la República se adorne otra vez con su bandera y sus constelaciones - se ve como una posibilidad deseada pero poco probable (como sugiere el imperfecto de subjuntivo). Si antes en su degradación «ya no cantabas, ni eras feliz, ni pura», el día de su liberación retomará su canto, que será también «el canto de las demás naciones». El coro de las naciones, alumnas distinguidas de la civilización occidental, será belleza y orden, fuerza e inocencia.

Como visión política, «De un argentino a la República» es alucinante; como poema, es tierno y conmovedor. Inaudita en la poesía argentina de este siglo es esta mezcla de amor patrio y amor sensual. En su visión de 1a Patria como una mujer celeste, recuerda a Spencer; en su desengaño y su esperanza, a Eliot. "Alumno distinguido» de Inglaterra, de Francia y de Italia, Wilcock siempre rechazó la visión nacionalista de la Argentina, aunque cantó desde su exilio su amor por la patria lejana: lejana por ideal, por sueño y profecía. 
